\title{
ACTION OF VARIOUS AGENTS ON RABBIT BLASTOCYSTS IN VIVO AND IN VITRO
}

\author{
G. LUTWAK-MANN, ${ }^{*}$ MARY F. HAY* AND D. A. T. NEW $\dagger$ \\ Agricultural Research Council Unit of Reproductive Physiology and Biochemistry,* \\ and Strangeways Research Laboratory, Cambridge
}

(Received 5th March 1968)

Summary. The action of various agents was investigated on 6-day-old rabbit blastocysts in vivo and in vitro. The blastocysts were examined by the flat-mount technique. The substances studied included antimetabolites (2-deoxyglucose, 2-deoxyglucose-6-phosphate, 2-deoxygalactose, 6-mercaptopurine and 6-mercaptopurine riboside, ethionine, isoniazid, analogues of vitamin $B_{12}$ ), enzyme inhibitors (DL-glyceraldehyde, salicylate, bromoacetylcarnitine, p-chloromercuribenzoate, fluoride), antimitotic agents (colcemid, aminopterin), cytostatic agents (actinomycin D, cytochalasin B), metabolites (DNA, glucose-6-phosphate, 2-deoxyribose, galactose), and hormones (polyoestriol phosphate, growth hormone). The influence of anoxia was also investigated, with special reference to temperature.

Agents which, under the experimental conditions laid down in this study, exerted clearly recognizable effects in vivo and in vitro, were 2-deoxyglucose, 6-mercaptopurine riboside, colcemid, isoniazid, aminopterin and DNA. Agents that were found to act in vitro only, were 2-deoxygalactose, glyceraldehyde, salicylate, bromoacetylcarnitine, 2-deoxyglucose-6-phosphate, actinomycin D, cytochalasin B, p-chloromercuribenzoate, and anoxia. An agent inert in vitro, but conducive (with longer exposure) to embryonic death in vivo, was polyoestriol phosphate. Growth hormone too, was inactive in vitro, but produced a slight effect in vivo. No effect was demonstrable in rabbit blastocysts following treatment with ethionine, analogues of vitamin $B_{12}$, fluoride, glucose-6phosphate, 2-deoxyribose, galactose.

Blastocysts, obtained from rabbits that had been subjected to embryotoxic agents (2-deoxyglucose, colcemid), were capable of recovery and further growth in vitro when the damage incurred in vivo was of a minor to moderate degree. Blastocysts moderately damaged by maternal 6-mercaptopurine or 6-mercaptopurine riboside treatment did not recover significantly; however, blastocysts more severely affected by these two compounds in vivo deteriorated further after incubation in vitro. Pretreatment of rabbits with polyoestriol phosphate yielded blastocysts which developed subsequently in vitro particularly well.

* Postal address: Animal Research Station, 307 Huntingdon Road, Cambridge.

† Present address: Physiological Laboratory, Downing Street, Cambridge. 


\section{INTRODUCTION}

Our earlier investigations on rabbit blastocysts were concerned chiefly with the effect upon the embryos of maternally transmitted agents, administered to pregnant animals in non-toxic doses (Adams, Hay \& Lutwak-Mann, 1961; Lutwak-Mann, Hay \& Adams, 1962; Lutwak-Mann \& Hay, 1962; LutwakMann \& Hay, 1964; Hay, 1964; Lutwak-Mann \& Hay, 1965a, b). Recently, as well as continuing the experiments in vivo, we have studied the direct action of certain classes of agents on rabbit blastocysts. The development in vitro of blastocysts that have previously been exposed to various agents in vivo has also been followed. We have undertaken a pilot survey which permits us to gather information on the action of a variety of different agents, rather than a study in depth.

Our experimental object was the 6-day-old blastocyst. The agents examined included metabolites, metabolic analogues, enzyme inhibitors, antimitotic and cytostatic compounds, and hormones. Some observations have also been made with respect to oxygen deprivation, particularly in relation to temperature. The flat-mount technique (Moog \& Lutwak-Mann, 1958; Adams et al., 1961; Lutwak-Mann \& Hay, 1967) was used to evaluate the viability and developmental progress of the embryos as well as to assess, within each blastocyst, the response to the treatment of the embryo proper as compared with extraembryonic tissue.

\section{MATERIALS AND METHODS}

\section{Animals}

The rabbits were bred and housed at the Animal Research Station. The number used in the experiments reported below was 106. The day of mating will be referred to as Day 0 .

\section{Experimental procedures}

These consisted of (1) experiments in vivo, in which blastocysts were recovered from rabbits subjected to various treatments, as specified in the text; (2) experiments in vitro, in which blastocysts were obtained from untreated rabbits and incubated in the presence of various additives listed in Table 1 ; (3) 'combined' in vivo-in vitro experiments, in which blastocysts obtained from rabbits treated in vivo, were subsequently allowed to develop further in vitro.

\section{Preparation of blastocysts for incubation experiments}

Entire uterine horns bearing blastocysts aged 6 days, taken from rabbits anaesthetized with pentobarbitone, were rinsed with cold saline and left unopened at $4^{\circ} \mathrm{C}$, until the embryos were removed for the incubation experiment (about $1 \mathrm{hr}$ ).

The nutrient medium was TC 199 to which was added $2 \mathrm{mg} / 100 \mathrm{ml}$ bovine plasma albumin. The blastocysts were incubated in small watch glasses containing $1 \mathrm{ml}$ of the nutrient medium so that the surface of the medium was about level with the top of the blastocysts. Up to four or five blastocysts were incubated 
in each watch glass; all comparisons between treated and control embryos were made on blastocysts taken from the same litter.

The watch glasses were housed in petri dishes containing gauze and $0.9 \%$ $\mathrm{NaCl}$ to maintain humidity, as in the standard method for tissue culture. The cultures were incubated at $37^{\circ} \mathrm{C}$ for periods indicated below, in a simple type of gas chamber (New, 1966), containing $95 \% \mathrm{O}_{2}$ and $5 \% \mathrm{CO}_{2}$, except in one experiment referred to later where oxygen was replaced by nitrogen. Sterile conditions were maintained throughout. At the end of the incubation, the blastocysts were fixed in methanol and processed for flat-mounts using albumen-coated coverslips.

\section{Histological examination}

The flat-mounts were coded and examined histologically by one of us (MFH) without prior knowledge of any treatment to which the blastocysts might have been exposed. The stage of development of the embryonic disc was determined as previously described (Adams et al., 1961; Lutwak-Mann et al.,

\section{TABLE 1}

\section{SUBSTANCES TESTED IN EXPERIMENTS IN VIVO ${ }^{a}$ AND IN VITRO ${ }^{b}$}

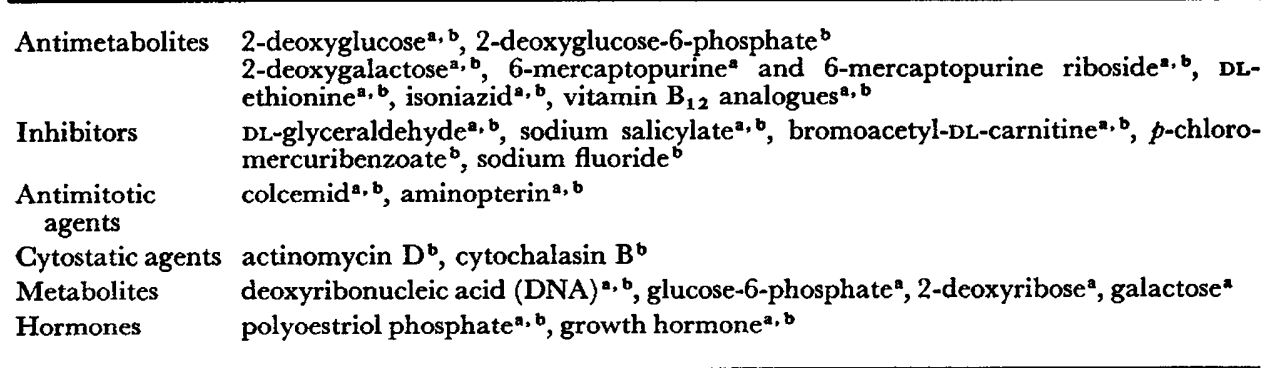

1962) and any abnormalities in size, shape or cytology (e.g. excessive amount of cellular degeneration) were recorded; the diameters of the intact blastocysts and the area of the embryonic disc were not usually measured in this study. The extra-embryonic tissue was examined for the presence of trophoblastic knobs and also for any histological or cytological anomalies; particular attention was paid to mitotic activity in the single layer of trophoblastic cells at the abembryonic pole. For simplicity we have recorded all observations on the extraembryonic tissue under the heading 'trophoblast' (see Tables 2, 3, 4 and 6), despite the fact that the two-thirds of the trophoblast lying closest to the embryonic disc is lined by endoderm, which was simultaneously examined. The occurrence of blastocyst collapse, which was also noted, made detailed analysis of flat-mounts difficult, and only general observations were possible in such cases.

\section{Agents examined}

Table 1 lists the substances used, in the order in which they are discussed in the text, and indicates the type of experiment in which each substance was tested. 


\section{RESULTS}

Tables 2, 3 and 4 summarize most of our experiments dealing with the effects exerted on rabbit blastocysts in vivo and in vitro by the various groups of agents listed in Table 1. In an effort to provide a more comprehensive survey a few of the data for results in vivo were taken from our earlier studies (Adams et al., 1961 ; Lutwak-Mann \& Hay, 1962, 1964, 1965a). No experiments in vivo were done with highly toxic substances, like actinomycin $\mathrm{D}$, cytochalasin $\mathrm{B}, p$ chloromercuribenzoate, and fluoride.

In P1. 1, Figs. A and B, the embryonic disc and trophoblast of rabbit blastocysts incubated for $7 \mathrm{hr}$ in nutrient medium without additives are shown. Histologically, these blastocysts do not differ significantly from normal (nonincubated) embryos (see, e.g., photomicrographs in Adams et al., 1961, and Lutwak-Mann \& Hay, 1967). Because it has been demonstrated before that the response of the disc (embryo proper) and trophoblast, respectively, to various agents can differ fundamentally, the results are given separately for each of these areas. Observations on mitotic activity and ability to maintain blastocoel expansion, are also included as they provide two further important criteria of embryonic survival.

Below, additional comments will be made on individual agents in each group, chiefly to bring out comparative aspects of the two types of experimentation; moreover, certain supplementary experiments will be presented, which were excluded from Tables 2, 3 and 4, as in some details the procedure involved departed from the routine one.

\section{ANTIMETABOLITES}

\section{2-Deoxyglucose $(2-D G)$}

This analogue was clearly deleterious to rabbit blastocysts both in vivo and in vitro (Table 2), but whereas in vivo its effect was typically limited to the disc (Lutwak-Mann \& Hay, 1965a), in vitro the trophoblast (Pl. 1, Fig. G) and the disc were affected and, in addition, mitosis was upset. Furthermore, whereas after parenteral administration the damage in the disc was visible within $2 \mathrm{hr}$, in vitro no effect was seen until after a longer exposure despite the relatively high concentration of 2-DG used. This perhaps indicates that, in vivo, a metabolic modification may increase 2-DG action on embryos.

\section{2-Deoxyglucose-6-phosphate (2-DG6P)}

This is the substance to which 2-DG must be converted to produce its inhibitory action on tissue metabolism (Barban \& Schultze, 1961). Experiments in vivo with 2-DG6P were omitted as it was anticipated that this P-ester would be rapidly dephosphorylated before reaching the embryos. In vitro, like 2-DG, it caused serious damage upon longer incubation, with the difference, however, that 2-DG6P affected the trophoblasts less than 2-DG, suggesting an ability of the trophoblast tissue either to utilize metabolic pathways not blocked by 2-DG6P or, alternatively, a dephosphorylating capacity towards this P-ester greater in the trophoblast than in the disc cells. 


\section{2-Deoxygalactose}

When given parenterally, at a dose-level like that of 2-DG, this analogue did not exert any effect on rabbit blastocysts. In contrast, in vitro (Pl. 1, Figs. D and E), it caused serious damage, namely degeneration of discs, arrest of mitosis and collapse of blastocyst cavity (Table 2). It seems, therefore, that in the rabbit, 2-deoxygalactose, though very toxic when acting directly, is metabolized in the body in such a way as to be inert in vivo. As can be seen from Table 4, galactose, too, was without influence on rabbit blastocysts in vivo.

\section{6-Mercaptopurine riboside (6-MPR)}

In earlier studies (Adams et al., 1961), we have described in detail the effect which 6-MP induces in rabbit blastocysts upon maternal transmission. However, as low solubility makes 6-MP rather unsuitable for experimentation in vitro, it was replaced by 6-MPR, which was also examined in vivo.

As can be seen from Table 2, 6-MPR is distinctly embryotoxic in vivo, but at a dose-level some ten times lower than that previously established for 6-MP. The maternal treatment for $48 \mathrm{hr}$ resulted in blastocysts with rather immature discs, but the trophoblasts were normal. In blastocysts exposed for a longer time 6-MPR caused almost complete disappearance of the discs, as well as a certain amount of trophoblast degeneration. The trophoblast cells were often enlarged, an effect typical of 6-MP, and occasionally contained two large nuclei. Some abnormal, but also some normal, mitotic figures were seen.

Blastocysts incubated in vitro with this agent showed no significant changes at $2 \mathrm{hr}$, but after $7 \mathrm{hr}$ all discs contained numerous degeneration granules. The trophoblasts remained relatively healthy and still contained dividing cells.

\section{Ethionine}

This amino acid analogue produced no significant effects on the blastocysts either in vitro or in vivo when given early in pregnancy, even at doses which were rather toxic to the rabbit.

\section{Isoniazid}

Rabbit blastocysts have been shown (Kodicek \& Lutwak-Mann, 1957) to contain strikingly large amounts of nicotinic acid, presumably in the form of coenzymes. It was, therefore, of interest to examine the effects of an analogue such as isoniazid on rabbit blastocysts.

When isoniazid was given to rabbits soon after mating, in doses up to 900 $\mathrm{mg} / \mathrm{kg}$, the blastocysts recovered from these animals were retarded, small for their age and poorly differentiated. Two typical experiments from a larger series, are shown in Table 2. Attempts were made to reverse the detrimental action of isoniazid, by giving rabbits simultaneous injections of either pyridoxin or niacin. There was some indication of successful reversal, but the differences observed were not considered sufficiently significant to warrant further study.

Some degeneration, as indicated in Table 2, was evident in the discs of blastocysts exposed to isoniazid in vitro. There was also some effect on the extraembryonic tissue, namely vacuolization of trophoblast cells and pyknosis of 
endodermal nuclei. Some blastocysts had few dividing cells, but others showed normal mitotic activity.

Vitamin $B_{12}$ analogues

Experiments with analogues of vitamin $B_{12}$ were of interest because it has been shown (Jacobson \& Lutwak-Mann, 1956) that, in the rabbit, the blastocyst fluid and the endometrial secretion are exceptionally rich in vitamin $B_{12}$.

The experiments in vivo presented in Table 2, were done with analogues such as $B_{12}$ anilide, methylamide and ethylamide. Even after prolonged periods of treatment no untoward results were observed on blastocysts. For the experiment in vitro the analogue used was 2-amino-2-methyl-propanol $\mathrm{B}_{12}$; however, even at a concentration of $0.5 \mathrm{mg} / \mathrm{ml}$, no deleterious effect was seen after a 7-hr incubation; on the contrary, if anything, the blastocysts kept in the presence of this anti-B $B_{12}$ compound looked slightly more healthy than their controls.

\section{INHIBITORS}

\section{DL-Glyceraldehyde}

Because of its low solubility glyceraldehyde is rather difficult to use in experiments involving parenteral administration. Doses of up to $450 \mathrm{mg} / \mathrm{kg}$ injected s.c. in warm aqueous solution were tolerated by rabbits reasonably well, but only short-term experiments were done to avoid formation of sores at the injection sites.

As recorded in Table 3, blastocysts from rabbits treated early in pregnancy showed only minor degrees of developmental anomaly. However, when blastocysts were incubated in the presence of glyceraldehyde, marked abnormalities in the discs and, to an even greater extent, in the trophoblasts were already evident after $2 \mathrm{hr}$. Round the posterior edge of the discs there were large cells with pyknotic nuclei. Mitosis was clearly affected in the trophoblasts; there were more prophases than usual, frequently abnormal, and some metaphases, but no anaphases or telophases were seen. After 7-hr incubation the abnormalities seen earlier were further intensified. The discs were thin and looked abnormal with signs of degeneration. It was striking to note the damage in the trophoblasts (Pl. I, Fig. F), usually the more resistant tissue; often nucleoli could not be seen in the resting cells and some nuclei were disappearing, leaving 'ghost-like' relics; mitotic activity was severely upset, there being no anaphases or telophases.

DL-Glyceraldehyde is known to interfere with phosphorylation of sugars in tissues, not directly but after conversion by aldolase into inhibitory products. Originally DL-glyceraldehyde was described by Mendel (1929) as an inhibitor of tumour glycolysis and, recently, interest in this respect was revived by Warburg (1964), who claimed that both D- and L-glyceraldehyde possess oncolytic effects. It is, therefore, of some significance to note that, in blastocysts, the damaging action of glyceraldehyde was directed predominantly against the trophoblast, a tissue that in its general resistance and invasive powers is often thought to exhibit tumour-like properties. 


\section{Salicylate}

When non-toxic amounts of salicylate were given parenterally to several rabbits early in pregnancy, no visible changes were recorded in the blastocysts (Table 3), although it has been shown (Lutwak-Mann, 1962) that maternally administered salicylate readily penetrates the blastocoel from which it is cleared rather more slowly than from maternal body fluids.

After incubation in vitro with $1 \mathrm{mg} / \mathrm{ml}$ (approximately five times more than we found in blastocyst fluid after maternal administration), only minor abnormalities were seen after $2 \mathrm{hr}$ exposure, probably some mitotic arrest, as no anaphases or telophases were noted. However, after $7 \mathrm{hr}$ the adverse effect of salicylate was magnified, when general retardation was seen in the discs as well as sick-looking trophoblasts, with cell division halted, and pathologically empty nuclei (Pl. 2, Figs. G and $\mathrm{H}$ ).

\section{Bromoacetylcarnitine}

This compound has been described as a potent inhibitor of carnitine acetyltransferase (Chase \& Tubbs, 1966), an enzyme system particularly active in the male reproductive tract and in spermatozoa (Marquis \& Fritz, 1965), but not as yet investigated in the female genital tract.

With the limited amounts of material available only low doses were examined in vivo. As can be seen from Table 3, such treatment had no effect on rabbit blastocysts.

Blastocysts that were incubated in the presence of $0.2 \mathrm{mg} / \mathrm{ml}$ for $2 \mathrm{hr}$ had discs which were still normal, but cell division had clearly been affected in the trophoblasts; there were numerous abnormal metaphases, no anaphases and probably some abnormal telophases (PI. 2, Fig. I). The last may signify an effect on nuclear reconstruction. After incubation for $7 \mathrm{hr}$, there was trophoblast collapse and the blastocysts were severely affected. Cellular shrinkage prevented detailed analysis, but the discs were not easily distinguishable. Mitoses were difficult to observe, but large prophase nuclei were visible and abnormal telophases, but no anaphases; metaphases, if present, could not be distinguished from pyknotic nuclei.

When the blastocysts were incubated at a concentration ten times lower, bromoacetylcarnitine produced much the same effects as described above, except that there appeared to be an absence of nuclear pyknosis.

Nothing is known so far about carnitine acetyltransferase in mammalian embryos. There is no doubt that a vital system in the blastocysts was seriously blocked by this inhibitor in vitro. It would, therefore, be important to repeat the experiments in vivo at a substantially higher dose-level when the compound becomes freely available.

\section{p-Chloromercuribenzoate}

This powerful mercaptide-forming inhibitor caused blastocyst collapse after $2 \mathrm{hr}$ (Table 3) when applied at a concentration of $10 \mu \mathrm{g} / \mathrm{ml}$, and progressive deterioration was evident after $7 \mathrm{hr}$. In embryos incubated for $2 \mathrm{hr}$, the cells appeared to have lost their cohesion and rounded up; nuclei were dense and 


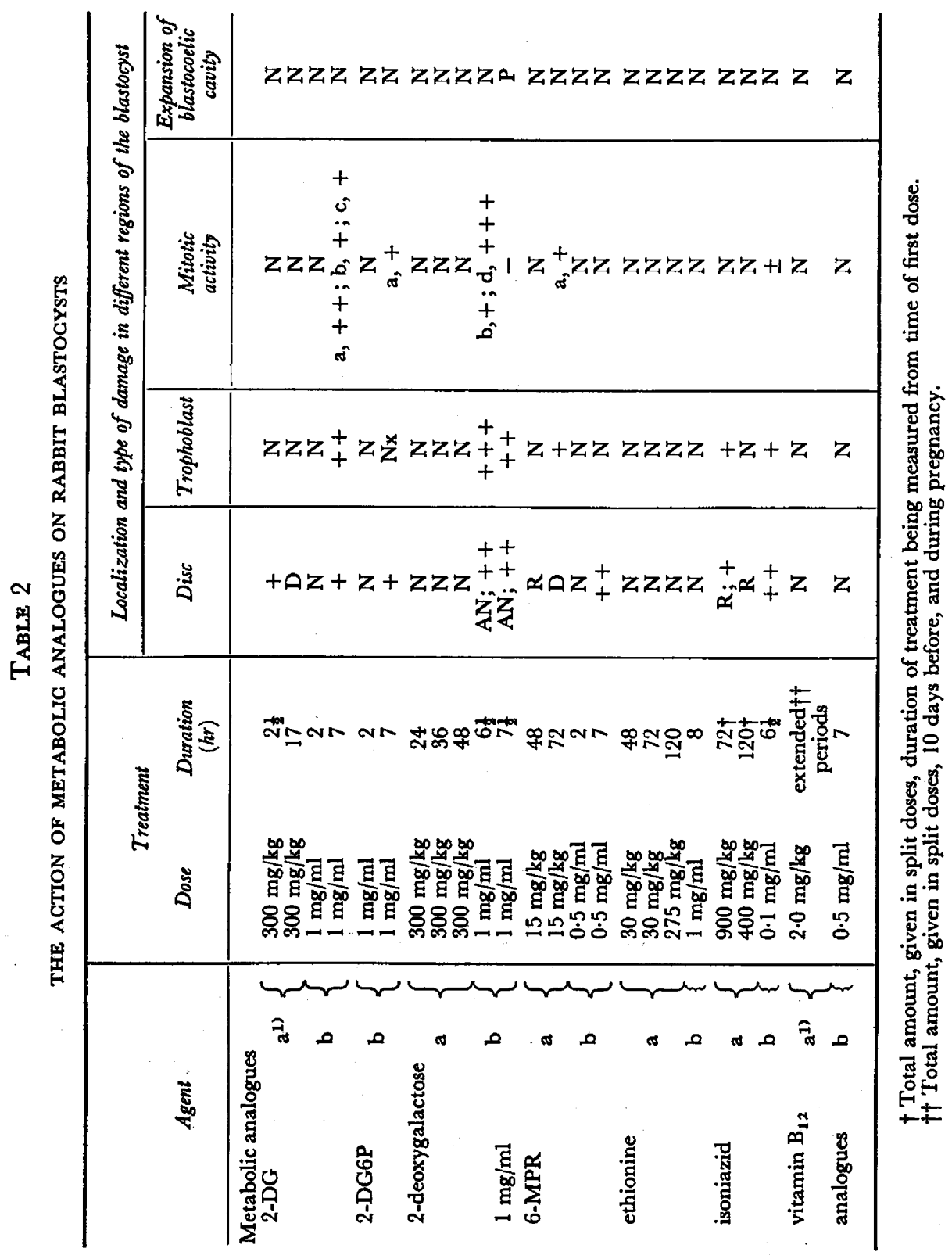




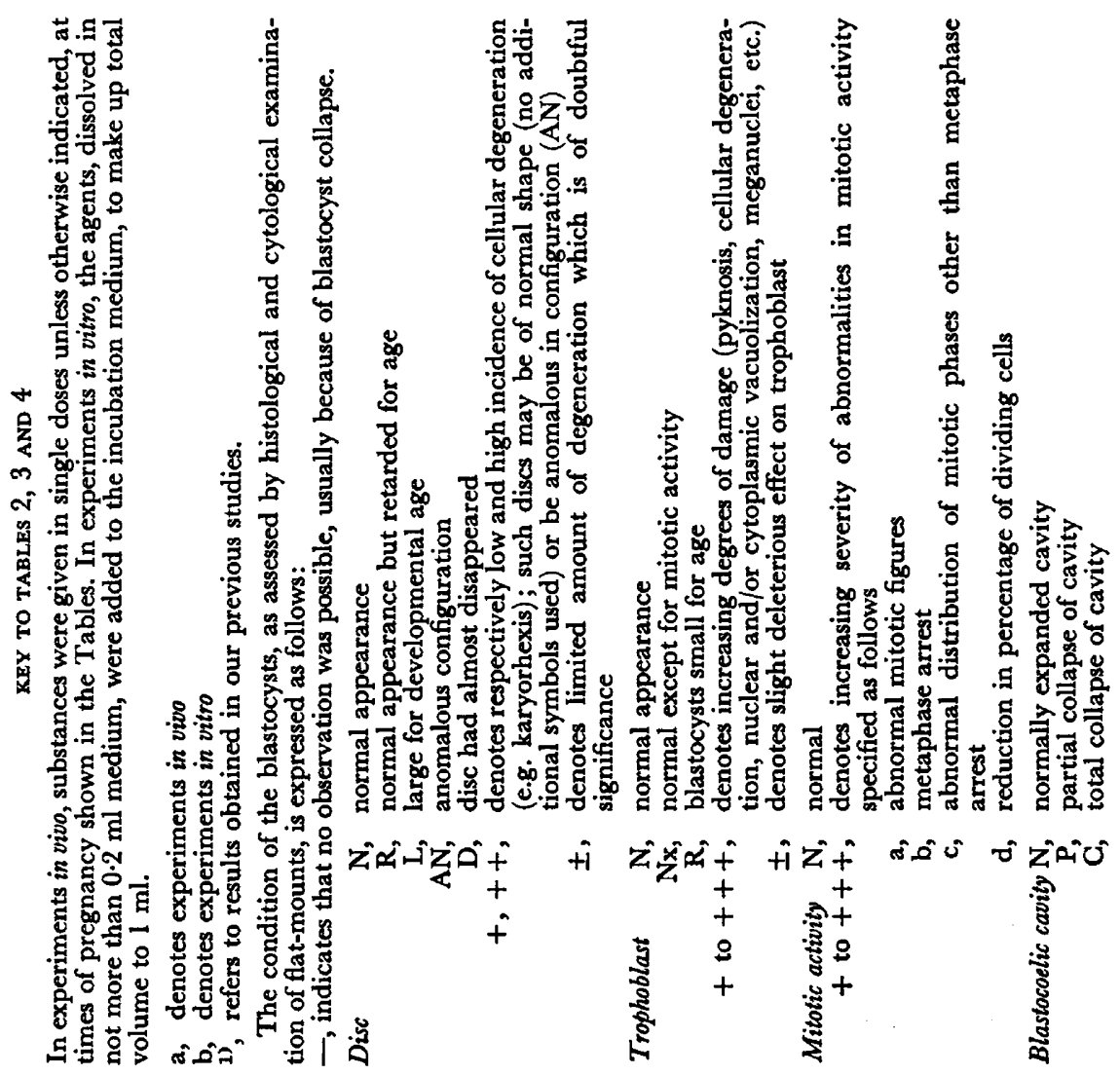




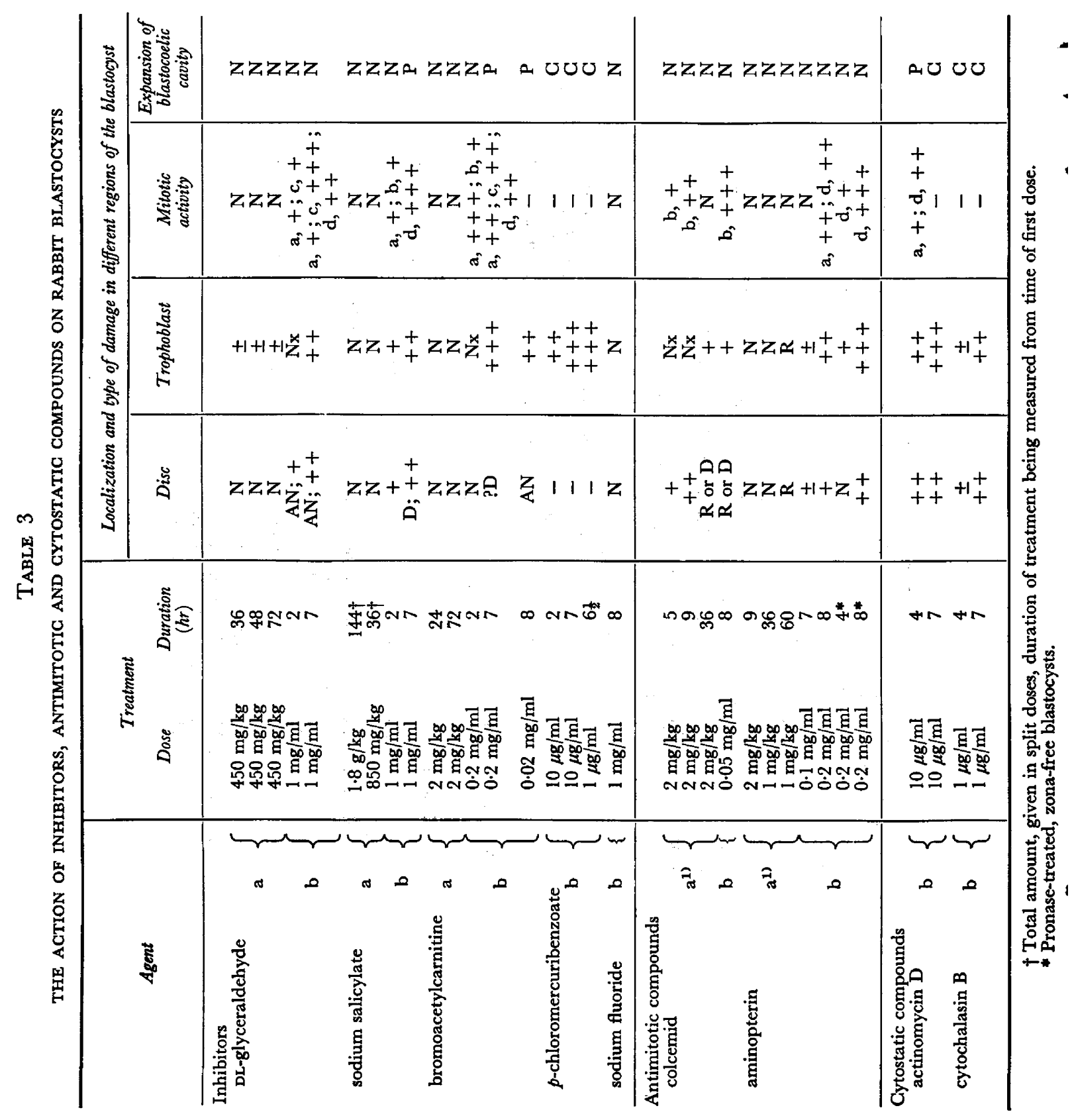




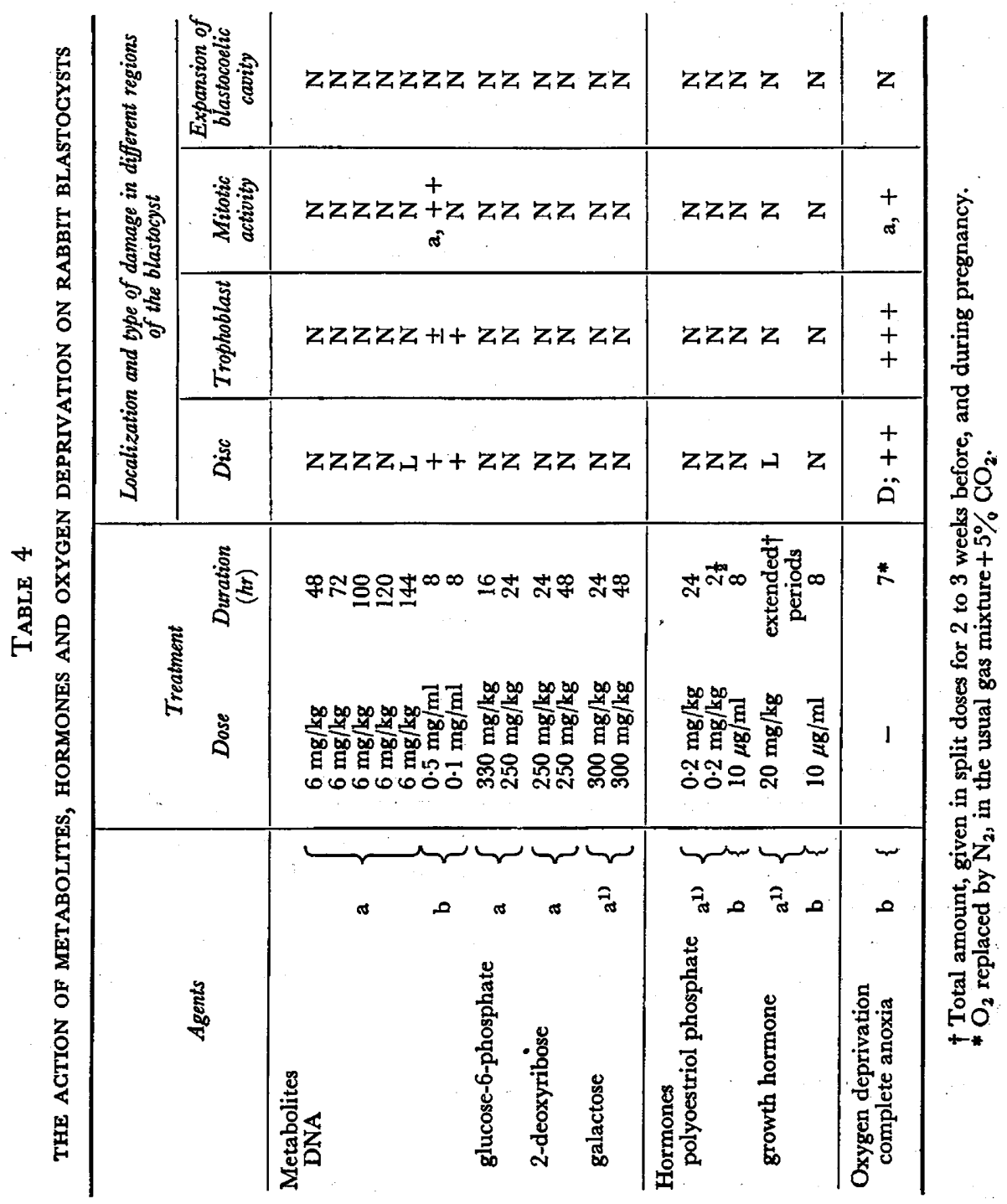


granular, nucleoli could not be seen. These changes were accentuated at $7 \mathrm{hr}$ and there was indication of nuclear breakdown.

Even at a concentration of $1 \mu \mathrm{g} / \mathrm{ml}$, there was blastocyst collapse in all embryos after $6 \frac{1}{2} \mathrm{hr}$. The tissue was so contracted that detailed analysis of the flat-mounts was not feasible. No normal mitoses were seen. Only in one out of five embryos was it possible to distinguish the disc, which looked abnormal but was not degenerate.

It may be relevant to add that rabbit blastocyst fluid is poor in SH-group containing compounds (Lutwak-Mann \& Short, unpublished), and contains relatively little cystine and methionine (Lutwak-Mann, 1966). The progestational endometrium, on the other hand, is very rich in SH-group containing compounds (Lutwak-Mann, unpublished). It is conceivable therefore that, in vivo, the endometrium might to some extent protect blastocysts against the action of toxic agents which bind functionally important thiol groups.

\section{Sodium fluoride}

Fluoride was devoid of effect on rabbit blastocysts at a concentration of 1 $\mathrm{mg} / \mathrm{ml}$ (Table 3 ). Whether the relatively high content in the nutrient medium of $\mathrm{Ca}$ and $\mathrm{Mg}$ ions had anything to do with the lack of effect exhibited by this enzyme inhibitor, is not known. But it may be of interest to note that in experiments with 2-cell mouse embryos (Thomson, 1967) development in vitro was only partly blocked by $0.01 \mathrm{M}$-fluoride.

\section{ANTIMITOTIC AGENTS}

\section{Colcemid}

We have previously investigated various phases of action of maternally transmitted colcemid (Adams et al., 1961). When injected into rabbits in low doses, colcemid promptly induces generalized metaphase arrest in the blastocysts, best seen in the trophoblast, and a certain degree of disc degeneration (Table 3). The metaphase arrest wears off after about $14 \mathrm{hr}$, but usually the damage to the disc is not reversed; occasionally retarded, but otherwise normal blastocysts result.

A comparable effect was seen in blastocysts exposed to colcemid in vitro for $8 \mathrm{hr}$. The discs were visibly affected and were mostly small and thickened (Pl. 2, Fig. J). A high proportion of trophoblast cells were in metaphase, indicating that the blastocysts were fixed at a point when the antimitotic agent was exerting a near-maximal effect (Pl. 2, Fig. K).

\section{Aminopterin}

In the rabbit, maternally administered aminopterin was almost without effect on the blastocysts (Table 3); methotrexate, another closely related antifolic antagonist and antimitotic agent, was also devoid of embryotoxic potency in this species (Adams et al., 1961).

Earlier attempts (Moog \& Lutwak-Mann, 1958) to induce changes in cell division in rabbit blastocysts in vitro during brief periods of incubation with aminopterin were not successful. In the present study, we have done longer 
incubations at two concentrations of aminopterin; in addition, to make the blastocysts more accessible, we have removed the zona pellucida from some blastocysts by treatment with pronase.

Incubation for $7 \mathrm{hr}$ with $0.1 \mathrm{mg} / \mathrm{ml}$ produced only minor degenerative changes and no effect on mitosis (Table 3). However, incubation for $8 \mathrm{hr}$ with $0.2 \mathrm{mg} / \mathrm{ml}$ resulted in clearly recognizable inhibition of cell division (Pl. 2, Fig. L), and some degeneration in the discs. With the zonasfree blastocysts, and at the same aminopterin concentration, there was a slight effect in $4 \mathrm{hr}$, but after $8 \mathrm{hr}$ incubation degeneration was obvious in discs and trophoblasts, and very few mitoses were seen.

It seems, therefore, that to induce distinctly recognizable effects in rabbit blastocysts in vitro, aminopterin must act for a sufficient length of time and at a suitable concentration. The removal of the zona pellucida may speed up its action.

\section{GYTOSTATIC AGENTS}

\section{Actinomycin D}

Actinomycin was markedly toxic to blastocysts at a concentration of $10 \mu \mathrm{g} / \mathrm{ml}$ (Table 3), causing partial collapse after $4 \mathrm{hr}$ incubation, and probable degeneration in both the discs and trophoblasts, although these were difficult to examine in detail. After longer exposure, complete collapse occurred in all embryos which were much more severely affected than the earlier group and very degenerate.

\section{Cytochalasin $B$}

Two kinds of experiments were done with this new type of 'cell-relaxant' compound (Carter, 1967; Aldridge, Armstrong, Speake \& Turner, 1967). First, a routine incubation was run to determine the concentration at which cytochalasin B would show distinct effects on rabbit blastocysts. At a concentration of $1 \mu \mathrm{g} / \mathrm{ml}$, cytochalasin B caused collapse in all blastocysts after $4 \mathrm{hr}$ (Table 3). Because of that, the flat-mounts were difficult to study, but the discs could still be seen without major signs of degeneration. After $7 \mathrm{hr}$ there was complete collapse in all embryos; in addition, at this stage there was very obvious degeneration in the discs, and also in the surrounding areas of the trophoblast. This indicates that, notwithstanding the early onset of trophoblast collapse, the degenerative processes in the discs continued to progress upon longer exposure to cytochalasin $\mathbf{B}$.

Next, attempts were made to reverse the deleterious effect of cytochalasin B by washing the embryos after different intervals of incubation, and transferring them to a cytochalasin-free medium for further development.

Three experiments were done as set out below; the concentration of cytochalasin B was $0 \cdot 1 \mu \mathrm{g} / \mathrm{ml}$, and the entire incubation period was $8 \mathrm{hr}$.

Experiment 1. Blastocysts in Group a) were incubated with cytochalasin during the entire incubation period, to provide evidence of the damage incurred under such conditions. Another group of blastocysts was first incubated with cytochalasin for $45 \mathrm{~min}$; it was then divided into Group b), which was fixed, to show the extent of damage at this point, and Group c), which was washed twice 
with medium at $37^{\circ} \mathrm{C}$, and allowed to complete the full incubation in cytochalasin-free medium.

All Group a) embryos exhibited total trophoblast collapse, making detailed assessment impossible; however, far-reaching degeneration was evident, chromatin fragments being obvious.

Group b) showed early stages of degeneration in the discs and also in the trophoblasts which contained chromatin granules (Pl. 3, Fig. M). Rather few dividing cells were seen. Compared with Group a), the Group b) embryos were in every respect less affected.

Group c), unlike Group a), did not develop trophoblast collapse, which indicates successful reversal in this respect. These embryos exhibited variable early stages of disc degeneration. In the trophoblasts, there was an accumulation of metaphases, some of which were breaking down (Pl. 3, Fig. N); a few normal anaphases were present. Altogether, the Group c) blastocysts were distinctly healthier than Group a). Even after removal of cytochalasin, however, adverse effects seemed to progress: Group c) was worse than Group b).

Experiment 2. Group a) blastocysts were incubated without cytochalasin, as a control. Another group was first incubated with cytochalasin for $45 \mathrm{~min}$ and then divided into Group b), which was fixed, and Group c), which was washed and transferred to normal medium.

Group a) showed normal development.

Group b) had affected discs and trophoblasts, but there was remarkable variability in type and extent of degeneration. Some discs showed unusual patchy degeneration. Nuclear fragmentation was seen in some trophoblasts. Cell division was upset. Moreover, disorganization was evident in the cell arrangement of the trophoblast, a process which ultimately may have been responsible for the collapse of this tissue, possibly owing to the action of cytochalasin B on cell membranes; cell boundaries, usually very distinct at the abembryonic pole, were not visible.

Group c) had some degenerative changes in the discs and trophoblasts. Mitosis was upset, possibly owing to a metaphase block which may have been wearing off by the time the embryos were fixed, after several hours of incubation in a normal medium. On the whole, these embryos were distinctly better than if they had been left with cytochalasin for the entire incubation period.

Experiment 3. Group a) blastocysts were incubated without cytochalasin. Two groups, b) and c), were incubated with cytochalasin, for $20 \mathrm{~min}$ and $100 \mathrm{~min}$, respectively, and were then washed and transferred into normal medium.

Group a) showed normal development.

Group b) showed only a slight degree of disc degeneration, and trophoblast collapse did not occur. In the trophoblasts, however, there was a wide range of effects, from severe degeneration in some, to slight in other embryos. Severely vacuolated nuclei were a pronounced feature of the trophoblasts.

Group c) was somewhat more affected than b), but here too, trophoblast collapse was prevented. The discs were small and full of degeneration granules. Also there was vacuolization in the trophoblasts.

The ability to maintain blastocoel expansion during incubation in vitro is an important indicator of embryonic viability. Exceedingly low concentrations of 
cytochalasin B induced a loss of this ability in a manner not as yet understood. However, when the blastocysts were exposed for relatively short periods, washed, and subsequently allowed to continue development in normal nutrient medium, the collapse of the blastocoel was prevented, though other signs of generalized degeneration were not thereby entirely eliminated. Another feature observed in experiments with cytochalasin $B$, was the differential effect on the extra-embryonic tissue, namely a decline in the severity of degeneration towards the abembryonic pole of the blastocysts.

\section{Deoxyribonucleic acid $(D \mathcal{N} A)$}

\section{METABOLITES}

Using a highly purified preparation of DNA from soft herring roe, we have made the following observations (Table 4). In experiments in vivo, it was found that rabbits tolerated well injections of neutralized solutions of DNA, given in single doses, early in pregnancy. Treatment on the day of mating, and therefore of long duration, resulted in blastocysts that appeared normal, except that, in some, the area of the disc was above the average value for the embryonic age and stage of differentiation. It is thought that this type of discrepancy may ultimately result in embryonic loss. White cells were seen on the zona pellucida in all blastocyst batches. Treatment on either Day $3 \frac{1}{2}$ or $4 \frac{1}{2}$ did not interfere with blastocyst development; the embryos appeared normal, but again clusters of white cells were seen outside the zonae of many. It may be mentioned that white cells are occasionally encountered in flat-mounts of blastocysts from untreated rabbits. In the case of DNA-treated animals leucocytosis was not unexpected, and was probably responsible for the white cells seen on the blastocysts, especially when the interval between DNA treatment and removal of blastocysts was short.

Some in vivo experiments with DNA, not included in Table 4, involved treatment of rabbits on Day 7 or 8 of pregnancy. These animals were allowed to go to term. The litters were apparently normal, but the number of young per litter was small, not exceeding four. This is low in the highly fertile does of our colony.

In connection with these findings, it may be mentioned that, in experiments on mice (Ledoux, Charles \& Srögl, 1967), it was found that, whereas exogenous DNA rapidly disappears from blood, it is readily absorbed by the female reproductive tract. However, as yet, there are no data on the uptake of DNA or its breakdown products by embryos in vivo.

In experiments in vitro, following incubation with $0.5 \mathrm{mg} / \mathrm{ml}$ there was disc degeneration above normal level. Moreover, in the trophoblasts there were some cells with fragmenting chromatin material (Pl. 3, Fig. O). Fragmentation may have been occurring at metaphase. There was a tendency for the discs of the treated blastocysts to be larger than controls. This recalls the findings made in vivo but, as an in vitro effect, it is thought to be of less significance than the dispersed chromatin.

Incubation with $0 \cdot 1 \mathrm{mg} / \mathrm{ml}$ also led to distinct degeneration in discs, which were somewhat retarded as compared with controls, as well as producing a severe degree of nuclear vacuolization in the trophoblasts. 
The findings on DNA toxicity to blastocysts in vitro gain in significance in view of the recent reports on the inhibition of tumour cell viability by DNA (Glick \& Salim, 1967). In these experiments, a high degree of specificity was demonstrated both as regards the nucleic acid and the tumour cell line.

\section{Glucose-6-phosphate, 2-deoxyribose, galactose}

These three metabolites, when given to rabbits at dose-levels indicated in Table 4, failed to produce any recognizable effects in the blastocysts.

\section{Polyoestriol phosphate}

In experiments of strictly limited duration (Table 4), no damage to blastocysts resulted from maternal treatment with polyoestriol.

When blastocysts were incubated for $8 \mathrm{hr}$ with $10 \mu \mathrm{g} / \mathrm{ml}$, no discernible effects were produced in either the discs or trophoblasts (Table 4). It is felt, however, that the incubation period may have been too short for hormonal influence to develop under such conditions.

\section{Growth hormone}

Early in vivo experiments were done with a partly purified preparation of bovine growth hormone (Lutwak-Mann \& Hay, 1962). This was administered daily for some weeks before mating and during pregnancy; the animals did not develop glycosuria. As can be seen from Table 4, the only effect of the treatment was to cause exceptionally large discs in some of the blastocysts.

For the experiments in vitro, a highly purified preparation of ovine growth hormone was used in a concentration of $10 \mu \mathrm{g} / \mathrm{ml}$. The treatment was without effect on blastocysts. As with oestrogen, so with this hormone, the period of treatment in vitro may have been too short to produce recognizable changes. Also, growth hormone might not have been able to act in vitro in a synthetic medium without the addition of insulin (Hay, 1958).

\section{OXYGEN DEPRIVATION}

Because a certain delay from the time of the animal's death to blastocyst removal from the uterus was unavoidable, we were interested in examining the extent of impairment incurred by the embryos in an increasingly anoxic environment, which they would encounter when left for some time in excised, but unopened, uterine horns. Accordingly, we have studied the effect on blastocysts of such increasingly anaerobic conditions chiefly in relation to temperature. In addition, a routine culture was run with blastocysts in completely anoxic conditions.

\section{Progressive anoxia}

Entire, unopened uterine horns containing blastocysts were separated at the cervical end and placed on saline-moistened filter paper in large petri dishes. One horn of each pair was incubated at $4^{\circ} \mathrm{C}$, the other at either $19^{\circ} \mathrm{C}$ or $37^{\circ} \mathrm{C}$, for $2 \frac{1}{2} \mathrm{hr}$. At the end of the incubation, the blastocysts were recovered from the 
uterine horns and fixed with methanol for flat-mount examination. Upon gross inspection it was noted that, whereas at $4^{\circ} \mathrm{C}$ the endometrium and the blastocysts appeared normal, at higher temperatures, especially at $37^{\circ} \mathrm{C}$, the blastocysts looked limp and were sinking below the folds of very oedematous endometrial mucosa, which was often covered with thin, faintly alkaline fluid, probably from leaking blastocysts. On addition of methanol to such blastocysts, unusually large amounts of protein were seen to coagulate in the blastocyst cavity, indicating, presumably, changes in the permeability of the embryos.

Blastocysts obtained from uterine horns kept at $4^{\circ} \mathrm{C}$, were, in general, quite healthy, except for mild degrees of nuclear vacuolization in the trophoblasts. Similarly, blastocysts from uterine horns kept at $19^{\circ} \mathrm{C}$, showed no major abnormalities. In contrast, blastocysts, left at $37^{\circ} \mathrm{C}$, showed far-reaching disorganization in discs and trophoblasts. This was evident as degeneration of the discs and shrunken cells in the trophoblasts with pyknotic nuclei; however, there were still a few dividing cells. It was interesting to note that, despite the extensive damage in these embryos, blastocoel expansion was preserved.

\section{Complete anoxia}

Blastocysts belonging to the same litter were incubated for $7 \mathrm{hr}$, one group in the routine manner, and the other with oxygen replaced by nitrogen, in the usual mixture with $5 \% \mathrm{CO}_{2}$.

The blastocysts in aerobic conditions were, as always, quite healthy; however, those incubated anaerobically had small and degenerate discs with severely vacuolated trophoblasts (Table 4). The vacuolization tended to be a gradient from severe vacuolization of whole cells near the disc (Pl. 3, Fig. P), to vacuolated nuclei at the equator (P1. 3, Fig. Q), to negligible near the abembryonic pole (Pl. 3, Fig. R), indicating, perhaps, different degrees of susceptibility to anoxia in these regions. It is noteworthy that mitotic activity was almost normal at the abembryonic pole under anaerobic conditions. This is of interest in view of the doubts that have been raised as to whether embryonic cells can enter mitosis under these conditions (Hughes, 1952).

DEVELOPMENT OF RABBIT BLASTOCYSTS IN VITRO AFTER EXPOSURE TO CERTAIN AGENTS IN VIVO

Having established, in a reproducible manner, the conditions for development in vitro of blastocysts obtained from normal rabbits, we wished to find out how, and to what extent, blastocyst development in vitro could be influenced by pre-treatment of the pregnant rabbits.

For animal treatment, we have chosen substances whose effects on blastocysts we knew precisely from previous experience, namely 2-DG, colcemid, 6-MP and 6-MPR, and polyoestriol-P. It was anticipated that the first four compounds would produce deleterious changes in the blastocysts in vivo but, according to the timing schedule, these could be graded to result in a smaller or greater degree of damage. Whether such damage was susceptible to repair in vitro, was what we set out to examine. With respect to polyoestriol, on the other hand, since it is well known that oestrogens stimulate endometrial 
metabolism, it was of interest to see whether subsequent development of the embryos in vitro could be enhanced.

\section{Experimental procedure}

Rabbits were treated with the aforementioned substances. On Day 6 of pregnancy the blastocysts were removed; half the embryos from each litter were fixed to provide information on the effect of the treatment in vivo, the

TABLE 5

DEVELOPMENT OF RABBIT BLASTOCYSTS IN VITRO AFTER EXPOSURE IN VIVO

\begin{tabular}{|c|c|c|c|}
\hline \multirow{3}{*}{$\begin{array}{l}\text { Exp. } \\
n o .\end{array}$} & I & II & III \\
\hline & \multirow{2}{*}{$\begin{array}{c}\text { Treatment of rabbits } \\
\text { Dose } \\
(\mathrm{mg} / \mathrm{kg})\end{array} \quad \begin{array}{c}\text { Duration } \\
(\mathrm{hr})\end{array}$} & \multicolumn{2}{|c|}{ Conditions of blastocysts } \\
\hline & & After exposure in vivo & After $8 \mathrm{hr}$ incubation in vitro \\
\hline $\begin{array}{l}1 \\
2 \\
3\end{array}$ & $\begin{array}{lr}2 \text { 2-deoxyglucose } \\
300 & 2 \frac{1}{2} \\
300 & 2 \frac{1}{2} \\
300 & 17\end{array}$ & $\begin{array}{l}\text { Typical early effect (disk) }+ \\
\} \text { damage (disc) }++\end{array}$ & $\begin{array}{l}\text { Good general recovery } \\
\text { Partial recovery }\end{array}$ \\
\hline $\begin{array}{l}4 \\
5 \\
6\end{array}$ & $\begin{array}{ll}\text { colcemid } & \\
2 & 2 \frac{1}{2} \\
2 & 2 \frac{1}{2} \\
2 & 18\end{array}$ & $\begin{array}{l}\text { Generalized metaphase arrest } \\
\text { Damage }++\end{array}$ & $\begin{array}{l}\text { Distinct recovery; meta- } \\
\text { phase arrest reversed } \\
\text { Partial recovery, less in } \\
\text { trophoblast than in disk }\end{array}$ \\
\hline 7 & $\begin{array}{l}\text { 6-mercaptopurine } \\
150 \quad 18\end{array}$ & \multirow[b]{2}{*}{\} Damage +++} & \multirow{2}{*}{$\begin{array}{l}\text { No deterioration, slight } \\
\text { improvement? } \\
\text { No recovery; deterioration }\end{array}$} \\
\hline $\begin{array}{l}8 \\
9\end{array}$ & $\begin{array}{l}150 \\
150\end{array}$ & & \\
\hline 10 & $\begin{array}{l}\text { 6-mercaptopurine } \\
\text { riboside } \\
15\end{array}$ & \multirow{3}{*}{$\begin{array}{l}\text { Damage }+ \\
\text { No damage (dose probably } \\
\text { too low) } \\
\text { Damage }+++\end{array}$} & \multirow{3}{*}{$\begin{array}{l}\text { No deterioration, slight } \\
\text { improvement? } \\
\text { No significant deterioration } \\
\text { No recovery; deteriora- } \\
\text { tion? }\end{array}$} \\
\hline 11 & 24 & & \\
\hline 12 & 15 & & \\
\hline $\begin{array}{l}13 \\
14\end{array}$ & $\begin{array}{l}\text { polyoestriol } \\
\text { phosphate } \\
0.05 \quad 2 \frac{1}{2} \\
0.05\end{array}$ & \} Normal & $\begin{array}{l}\text { Good development } \\
\text { Enhanced development }\end{array}$ \\
\hline
\end{tabular}

I, substances were administered by single injection; colcemid and 6-MP were given s.c., the others i.v. II, all experiments in vivo were terminated on Day 6 of pregnancy; half of each blastocyst litter was fixed immediately after removal from uterus.

III, findings refer to the other half of each blastocyst litter, fixed after incubation in vitro.

rest were incubated for $8 \mathrm{hr}$ under standard conditions, and then fixed. The results of these experiments, briefly summarized in Table 5, were as follows.

\section{2-Deoxyglucose $(2-D G)$}

Treatment in vivo for a short time only (Exps. 1 and 2) caused, in the blastocysts, the typical early 2-DG effect, namely degeneration in the discs but none 
in the trophoblasts. However, after incubation in vitro, in the absence of 2-DG, the embryos presented a markedly healthier appearance, and some even exhibited primitive streak formation, a stage of development that they would certainly not have attained had they been left in utero, where they would have continued to degenerate (Lutwak-Mann \& Hay, 1965a). These experiments indicate the ability of blastocysts to continue to differentiate owing to recovery in vitro from (early) effects of treatment in vivo with 2-DG, the extra-uterine repair being especially evident in the discs which are the main target of 2-DG action in vivo.

When 2-DG treatment lasted longer (Exp. 3), it produced far-reaching damage in the discs but practically none in the trophoblasts. After incubation in vitro, such blastocysts showed discs that still had an abnormal appearance, but the acute phase seemed over, and some of the embryos looked viable and as though they might be capable of further development. It appears therefore that, in spite of more extensive damage due to prolonged 2-DG action in vivo, some degree of repair and development was still possible in vitro.

\section{Colcemid}

Treatment of short duration (Exps. 4 and 5) caused, in the blastocysts, typical early effects of a mitotic poison acting in vivo, namely generalized metaphase arrest and some nuclear degeneration in the discs; in one experiment (Exp. 5) the configuration of the discs was also seriously affected. Following incubation in normal nutrient medium, though it was still evident that the embryos had been affected by earlier treatment, some discs were developing well, and showed only slight signs of degeneration, while others exhibited more serious defects. Moreover, unlike the non-incubated embryos, the trophoblasts had cells in all stages of division and there was no sign of metaphase arrest. Thus, the transfer to the culture medium enabled some recovery, both in the disc and trophoblast areas.

More extensive exposure to colcemid (Exp. 6) resulted in blastocysts which had thin discs, abnormal in shape, but not excessively degenerate; the trophoblasts contained degenerating cells and also an excessive number of dividing cells, an indication that the blastocysts at the time of autopsy were recovering in vivo from earlier mitotic inhibition. The incubated embryos, on the other hand, showed discs that were still abnormal morphologically but decidedly more healthy than in the non-incubated group, suggesting the possibility of further growth. The trophoblasts showed areas of degeneration and few dividing cells. In some blastocysts, however, trophoblastic knobs were forming, a sign of progressive development in spite of the preceding exposure in vivo. It is of interest to note that in this experiment in which, before culture, the blastocysts had been subjected to colcemid in vivo for a longer time, the trophoblasts appeared to have recovered in vitro rather less well than the discs.

\section{6-Mercaptopurine and 6-mercaptopurine riboside (6-MP and 6-MPR)}

These two closely related substances will be considered together, as they produced essentially similar results.

Shorter exposures in vivo to either 6-MP (Exp. 7) or 6-MPR (Exp. 10), 
resulted in blastocysts with immature and partly degenerated discs, and somewhat less seriously affected trophoblasts. On incubation in vitro, while there was no further deterioration, only a very minor degree of improvement was recognizable in the blastocysts. In Exp. 11, probably too low a dose of 6-MPR was used in vivo to bring about clear-cut signs of damage; moreover, there was no evidence of deterioration in vitro.

When, however, 6-MP or 6-MPR had acted in vivo for a longer time (Exps. 8, 9 and 12), the destruction of the discs was extensive; the trophoblasts, although showing areas of degeneration, still possessed some dividing cells. In the incubated blastocysts there was no evidence of recovery; if anything, there were fewer dividing cells, indicating progressive deterioration in these seriously damaged embryos.

\section{Polyoestriol phosphate}

In agreement with numerous earlier findings, the brief period of treatment in vivo with this oestrogen preparation (Exps. 13 and 14) did not affect the embryos at all. Following incubation in vitro, embryos in Exp. 13 showed normal discs and there was no indication of either stimulation or retardation of growth. In Exp. 14, however, trophoblastic knobs were developing, and the general impression was that these blastocysts from an oestrogen-pretreated rabbit were particularly well developed, as if some minor degree of growth enhancement had taken place.

\section{DISCUSSION}

The purpose of our investigation was twofold, namely (1) by using agents endowed with diverse biological potency to assess in a comparative manner their effects on rabbit blastocysts in vivo and in vitro, and (2) to find out whether, and to what extent, damage sustained by pre-implantation embryos in utero is susceptible to repair in vitro, and, on a parallel line of thought, whether one could influence beneficially the development of blastocysts in vitro by pretreating the donor animals, for example with an uterotrophic hormone. The experimental work was done on a pilot scale, to serve as a basis for a more detailed later investigation of points meriting further study.

For experiments with rabbit blastocysts in vivo, we were able to rely on experience gained over the years with this type of experimentation, which therefore requires no special comment. The short-term maintenance of rabbit blastocysts in vitro, under simple and readily reproducible conditions, is nowadays a standard procedure and thus poses no particular problems. No claim is made for the conditions adopted to be either optimal or generally applicable, and it is recognized that they might have to be materially altered if needed for embryos of a different developmental stage, or for extended periods of incubation.

The 6- to 8-hr total incubation period seems to have been adequate for our purpose. While it is possible that some agents, especially those of hormonal nature, might have displayed effects after longer periods of incubation, many of the active agents did, in fact, induce recognizable effects before the termination of the adopted time-span, some of them, notably cytochalasin B, causing marked damage within less than $1 \mathrm{hr}$ of incubation. In general, however, periods 
shorter than 6 to $8 \mathrm{hr}$ would have been insufficient because with some ultimately very potent agents, like 2-DG or 6-MPR, effects were not detectable at the earlier stages of incubation.

Because information about the effective concentration of the various additives is scarce, the concentrations we used were of necessity chosen rather arbitrarily. Only in a few instances were different concentrations compared, as when it was obvious that the agent examined was exceptionally active, e.g. cytochalasin B, bromoacetylcarnitine, $p$-chloromercuribenzoate, or conversely, as in the case of aminopterin, where clear-cut effects on cell division were not noticeable until the concentration of this antimitotic agent was raised to an effective level.

The comparative aspect of tests carried out both in vivo and in vitro is of interest. Our results make it clear that some agents, for instance 2-deoxygalactose or DL-glyceraldehyde, can be very toxic to rabbit blastocysts when acting directly, yet are metabolized in the maternal body in such a way as to become virtually harmless in vivo. These observations raise a general point about the significance of metabolic or pharmacological experiments with mammalian embryos in vitro, and indicate that the validity should probably always be substantiated by complementary evidence in vivo. Equally, it must be borne in mind that substances which appear devoid of activity on blastocysts of a given species, both in vivo and in vitro, as we have found for instance with ethionine, anti-B $B_{12}$ compounds or galactose, may turn out to be deleterious, in vivo at any rate, at the post-implantation stages of embryonic development.

With regard to the 'combined' in vivo-in vitro type of experiment, which involves pretreatment of blastocyst-donor animals and subsequent incubation of the embryos in vitro, our observations, though numerically limited, suggest that this is a promising approach and one that deserves further exploitation. It is interesting to note that in the case of certain agents, such as a metabolic analogue (2-DG) or an alkylating and antimitotic compound (colcemid), minor to moderate degrees of embryopathy acquired in utero are apparently amenable to repair by severing the maternal-embryonic association, and letting the embryos recuperate in a nutrient medium for a limited length of time. Such embryonic therapy in vitro could undoubtedly be made more effective than in our experiments so far, and might next be extended by transfer of the explanted embryos into appropriate recipients for resumption of physiological development. One can envisage such experiments being particularly worthwhile in cases of maternal exposure during early pregnancy, say to ionizing radiation, virus infection or severe malnutrition.

There is also considerable scope for future work in 'combined' in vivo-in vitro experiments devised so as to bring about enhanced in vitro growth of blastocysts by pretreating the pregnant animals, either hormonally, as we have attempted, or by other means, e.g. nutritionally, by increasing the maternal intake of certain vitamins or minerals.

\section{ACKNOWLEDGMENTS}

We acknowledge gratefully gifts of the following compounds, cytochalasin B (Dr S. B. Carter, I.C.I.); bromoacetylcarnitine (Dr P. K. Tubbs); DNA from herring roe (Professor R. Markham); actinomycin D (Merck, U.S.A.); 2-amino- 
2-methyl-propanol $\mathrm{B}_{12}$ (Dr W. Friedrich); polyoestriol phosphate (Leo,

Sweden); growth hormone (S-5, ovine, NIH)

We also wish to place on record the contribution made by Mrs M. Larkin, who prepared the blastocyst flat-mounts examined in this study.

\section{REFERENCES}

Adams, C. E., Hay, M. F. \& Lutwak-Mann, C. (1961) The action of various agents upon the rabbit embryo. 7. Embryol. exp. Morph. 9, 468.

Aldridge, D. G., Armstrong, J. J., Speake, R. N. \& Turner, W. B. (1967) The cytochalasins, a new class of biologically active mould metabolites. Chem. Commun. 26, 26.

Barban, S. J. \& Schultze, H. O. (1961) The effects of 2-deoxyglucose on the growth and metabolism of cultured human cells. 7 . biol. Chem. 236, 1887.

Garter, S. B. (1967) Effect of cytochalasins on mammalian cells. Nature, Lond. 213, 261.

CHAsE, J. F. A. \& TUBbs, P. K. (1966) Specific inhibitors of carnitine acetyltransferase and other acyltransferases. Biochem. 7. 100, 47.

Glick, J. L. \& SAlim, A. P. (1967) Inhibition of tumour cell viability by DNA. Nature, Lond. 213, 676.

HAY, M. F. (1958) The effect of growth hormone and insulin on limb-bone rudiments of the embryonic chick cultivated in vitro. F. Physiol., Lond. 144, 490.

HAY, M. F. (1964) Effects of thalidomide on pregnancy in the rabbit. 7. Reprod. Fert. 8, 59.

Hughes, A. (1952) The mitotic cycle, pp. 188-189. Butterworths, London.

Jacobson, W. \& Lutwak-ManN, G. (1956) The vitamin $B_{12}$ content of the early embryo. F. Endocr. 14, xix.

Kodicex, E. \& LUTwak-ManN, C. (1957) The pattern of distribution of thiamine, riboflavin and nicotinic acid in the early embryo. $\mathcal{F}$. Endocr. 15, liii.

Ledoux, L., Charles, P. \& SRögl, M. (1967) Fate of exogenous DNA in blood and hyperplastic genital tract of female mice. Nature, Lond. 214, 1241.

LuTWAK-MANN, G. (1962) Glucose, lactic acid and bicarbonate in rabbit blastocyst fluid. Nature, Lond. $193,653$.

LUTWAK-MANN, C. (1966) Some physiological and biochemical properties of the mammalian blastocyst. Bull. Schweiz. Akad. med. Wiss. 22, 101.

Lutwak-ManN, C. \& HAY, M. F. (1962) Effect on the early embryo of agents administered to the mother. Br. med. F. ii, 944.

LutwaK-MANN, C. \& HAY, M. F. (1964) Effect of certain water-soluble oestrogens on rabbit blastocysts. 7. Endocr. 30, ix.

Lutwak-MANN, G. \& HAY, M. F. (1965a) Effect of 2-deoxyglucose on the rabbit blastocyst. F. Reprod. Fert. 10, 133.

Lutwak-Mann, C. \& HAY, M. F. (1965b) Maternally transmitted embryotropic agents. In: Agents Affecting Fertility, p. 261. Eds. C. R. Austin and J. S. Perry. Churchill, London.

LUTWAK-MANN, G. \& HAY, M. F. (1967) The blastocyst flat-mount technique in studies on embryotropic agents. Adv. Teratol. 2, 229.

Lutwak-Mann, G., Hay, M. F. \& Adams, C. E. (1962) The effect of ovariectomy on rabbit blastocysts. 7. Endocr. 24, 185.

Marquis, N. R. \& Fritz, J. B. (1965) Effect of testosterone on distribution of acetylcarnitine and carnitine acetyltransferase in tissues of the reproductive system of the male rat. F. biol.Chem. 240, 2197.

MendeL, B. (1929) Krebszelle und Glycerinaldehyd. Klin. Wchschr. 8, 169.

Moog, F. \& LuTWAK-MANN, G. (1958) Observations on rabbit blastocysts prepared as flat-mounts. $\mathcal{F}$. Embryol. exp. Morph. 6, 57.

New, D. A. T. (1966) The culture of vertebrate embryos. Logos Press and Academic Press, London.

Thomson, J. L. (1967) Effect of inhibitors of carbohydrate metabolism on the development of preimplantation mouse embryos. Expl Cell Res. 46, 252.

Warburg, O. (1964) Prefatory chapter. A. Rev. Biochem. 33, 1.

EXPLANATION OF PLATES 1 TO 3

All preparations shown in these plates were stained with Delafield's haematoxylin.

PLATE 1

(Figs. A and D $\times 45$; Figs. B, C, E and F $\times 450$ )

Fig. A. Embryonic disc of a 6-day rabbit blastocyst incubated for $7 \mathrm{hr}$ in control medium. The disc is normal and is just beginning to grow out in a posterior direction (right-hand side of figure). 
PLATE 1
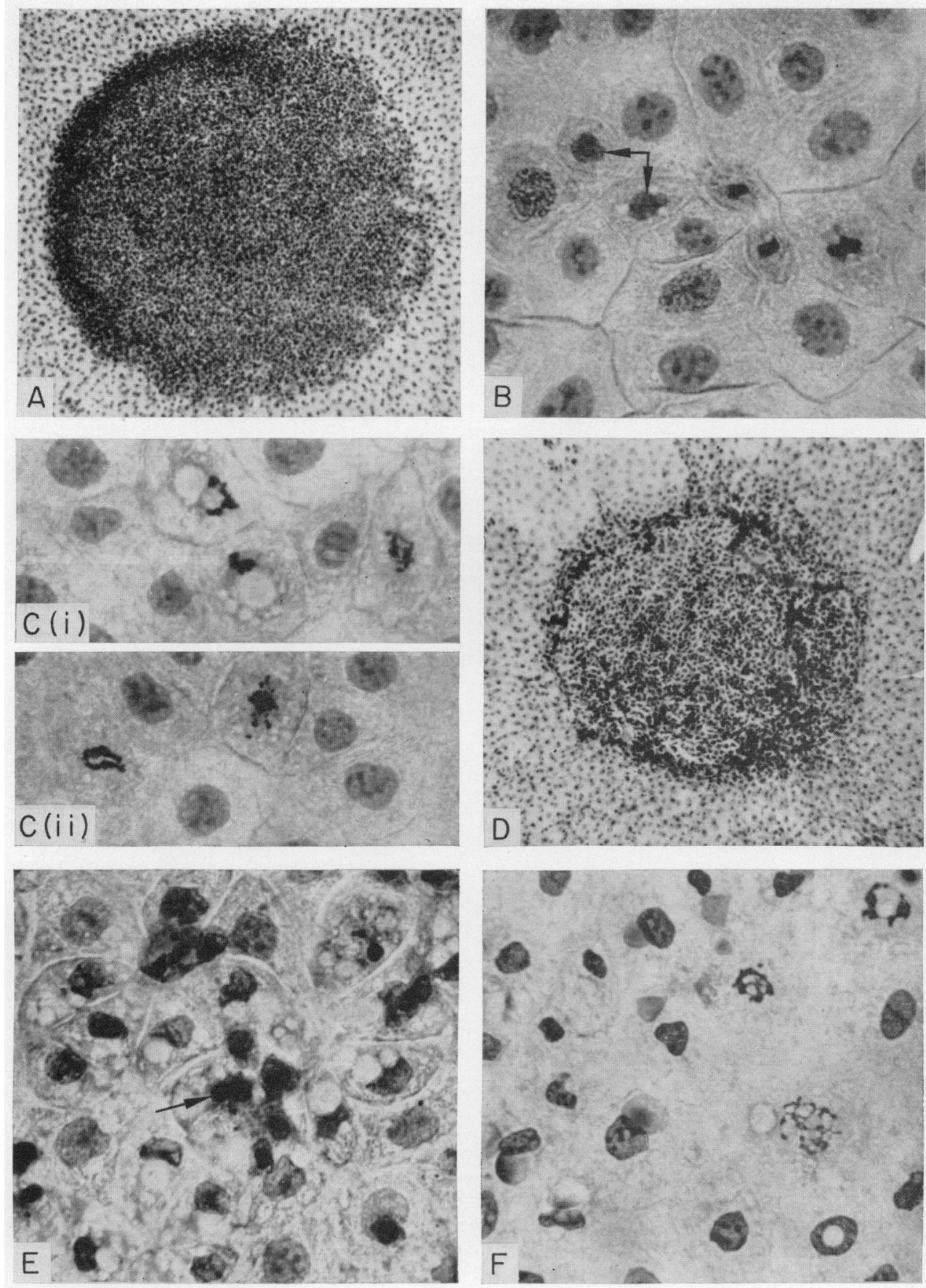

(Facing p. 256) 
PLATE 2
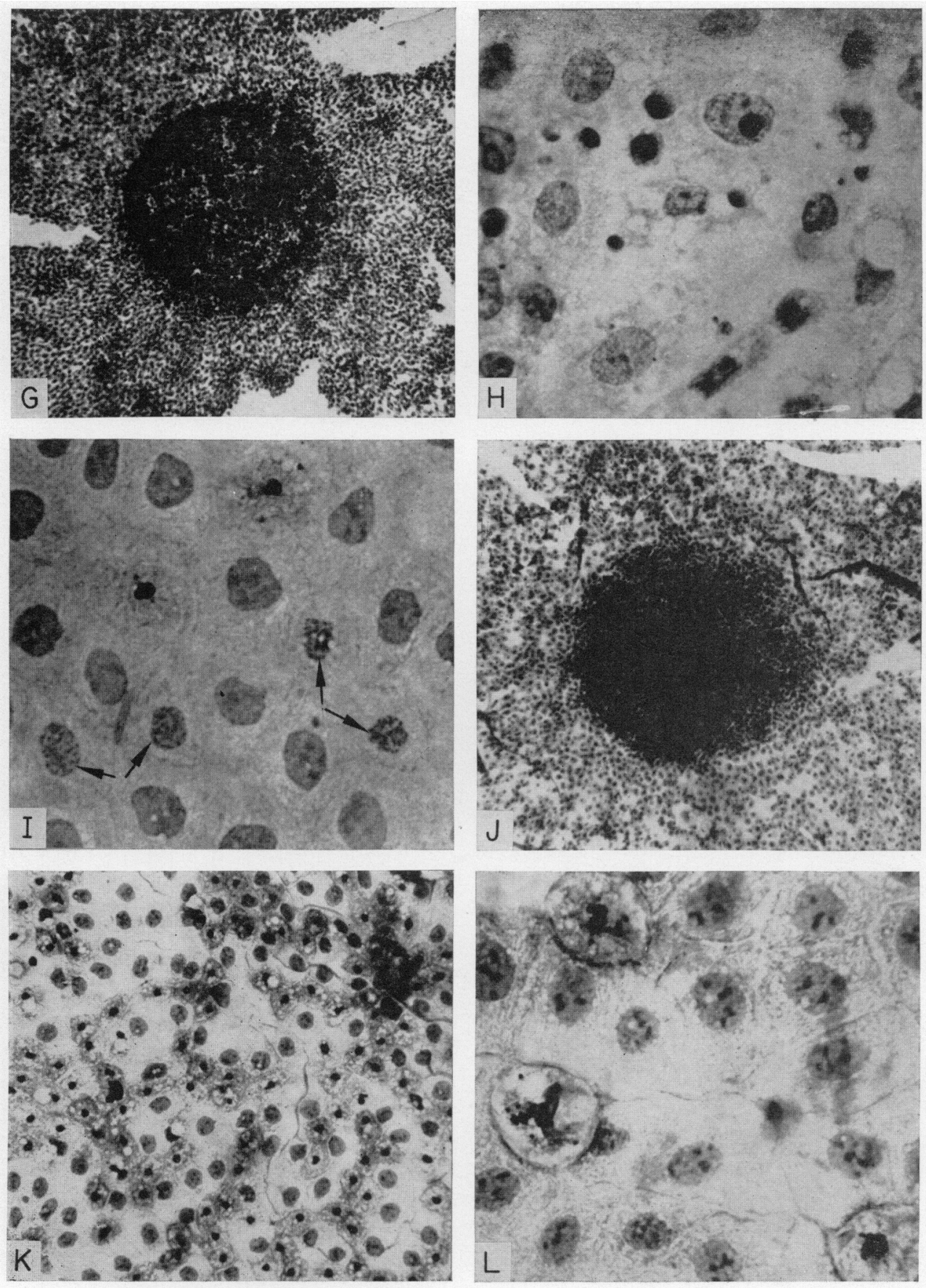
PLATE 3
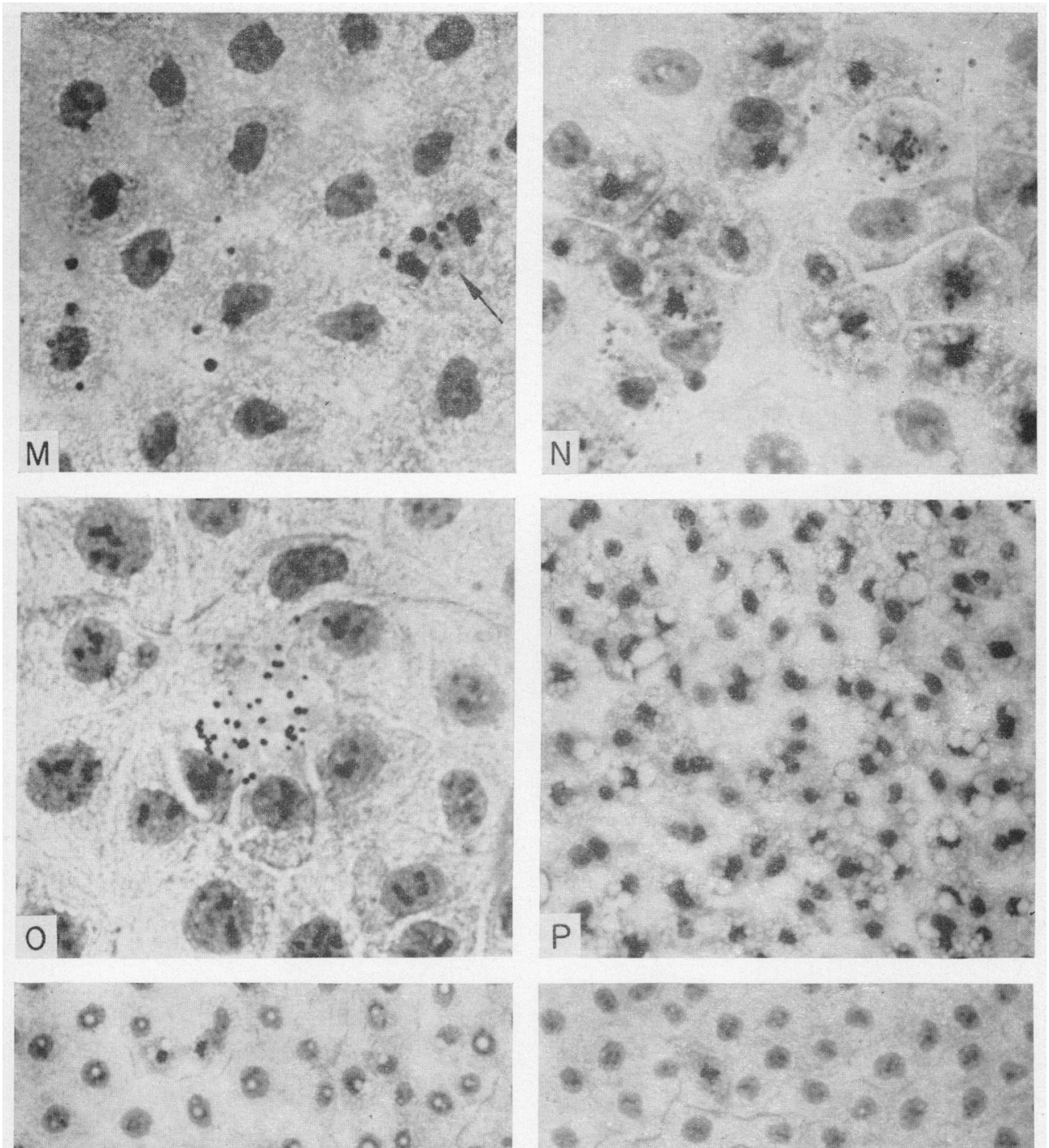

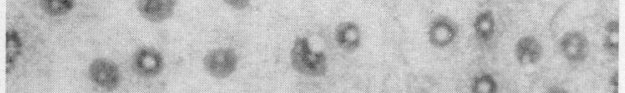
- $8008^{\circ} \circ$ - 0 o 0 * 0

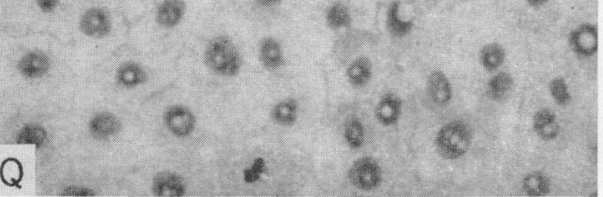

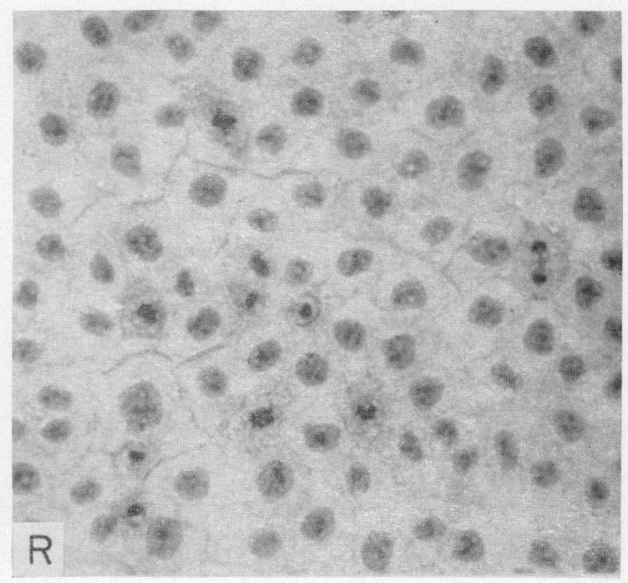


Fig. B. Part of the trophoblast from the abembryonic pole of a 6-day rabbit blastocyst incubated for $7 \mathrm{hr}$ in control medium. The resting nuclei contain several nucleoli. Some dividing cells can be seen: two prophases, a metaphase, a late anaphase and a pair of late telophase $(\uparrow)$ nuclei.

FIG. G(i) and C(ii). Part of the trophoblast from the abembryonic pole of a 6-day rabbit blastocyst incubated for $7 \mathrm{hr}$ in a medium containing $1 \mathrm{mg} 2$-deoxyglucose per $\mathrm{ml}$. In G(i) severely vacuolated dividing cells in metaphase can be seen; in $\mathrm{G}$ (ii) are two abnormal metaphases.

Figs. D and E. Embryonic disc and part of the extra-embryonic tissue of a 6-day rabbit blastocyst incubated for $6 \frac{1}{2} \mathrm{hr}$ in medium containing $1 \mathrm{mg} 2$-deoxygalactose per $\mathrm{ml}$. The disc (Fig. D) is small and thin and the inner layer of cells appears to be degenerating; $\mathrm{cf}$. Fig. A, a blastocyst from the same litter but incubated in control medium. In the extraembryonic tissue (Fig. E) only one dividing cell (metaphase, $\uparrow$ ) can be seen. The trophoblastic cells are severely vacuolated and the nuclei of some of the endodermal cells are pyknotic.

FIG. F. Part of the extra-embryonic tissue of a 6-day rabbit blastocyst incubated for $7 \mathrm{hr}$ in medium containing $1 \mathrm{mg} \mathrm{DL}$-glyceraldehyde per $\mathrm{ml}$. Many of the nuclei appear shrunken with an angular outline; others are represented by ghost-like relics which have lost their affinity for the dye. Three abnormal mitotic figures (one prophase, two metaphases) can be seen.

\section{PLATE 2}

(Figs. $\mathrm{G}$ and $\mathrm{J} \times 45$; Figs. $\mathrm{H}, \mathrm{I}$ and $\mathrm{L} \times 450$; Fig. $\mathrm{K} \times 180$ )

Figs. $G$ and $H$. Embryonic disc and part of the extra-embryonic tissue of a 6-day rabbit blastocyst incubated for $7 \mathrm{hr}$ in medium containing $1 \mathrm{mg}$ sodium salicylate per $\mathrm{ml}$. The disc (Fig. G) is small and somewhat thickened; cf. Fig. A. In the extra-embryonic tissue (Fig. H) there are two badly vacuolated cells and no dividing ones; several nuclei are pyknotic and some resting nuclei have a finely granulated appearance; cf. Fig. $\mathrm{B}$, a blastocyst from the same litter but incubated in control medium.

FIG. I. Part of the trophoblast from the abembryonic pole of a 6-day rabbit blastocyst incubated for $2 \mathrm{hr}$ in medium containing $0.2 \mathrm{mg}$ bromoacetylcarnitine per $\mathrm{ml}$. Cell division has already been affected; two abnormal metaphases are clearly visible; there are also two pairs of telophases $(\uparrow)$ with an abnormal, rather granular, appearance.

FIGs. J and K. Embryonic disc and part of the extra-embryonic tissue of a 6-day rabbit blastocyst incubated for $8 \mathrm{hr}$ in medium containing $0.05 \mathrm{mg}$ colcemid per $\mathrm{ml}$. The disc (Fig. J) is small and thickened; cf. Fig. A. The extra-embryonic tissue (Fig. K) contains many vacuolated cells; a large number of mitoses arrested in metaphase can also be seen.

FIg. L. Part of the trophoblast from the abembryonic pole of a 6-day rabbit blastocyst incubated for $8 \mathrm{hr}$ in medium containing $0.2 \mathrm{mg}$ aminopterin per ml. Cell division was blocked at metaphase; three abnormal mitotic figures in this stage are shown. This blastocyst was incubated without prior removal of the zona pellucida.

\section{PLATE 3}

(Figs. $M$ and $N \times 450$; Fig. $O \times 580$; Figs. $P, Q$ and $R \times 230$ )

FIG. M. Part of the trophoblast from the abembryonic pole of a 6-day rabbit blastocyst incubated for $45 \mathrm{~min}$ in a medium containing $1 \mu \mathrm{g}$ cytochalasin $\mathrm{B}$ per ml. The nuclei are slightly shrunken. Chromatin granules can be seen and there is also an anaphase ( $\uparrow$ ) which appears to be breaking down into granules.

FIG. N. Part of the trophoblast from a 6-day rabbit blastocyst incubated for $45 \mathrm{~min}$ in a medium containing $1 \mu \mathrm{g}$ cytochalasin $\mathrm{B}$ per $\mathrm{ml}$, and subsequently in a cytochalasin-free medium for $7 \mathrm{hr}$. Cell division was blocked in metaphase. Some metaphase figures appear normal, while others are clearly abnormal.

Fig. O. Part of the trophoblast from the abembryonic pole of a 6-day rabbit blastocyst incubated for $8 \mathrm{hr}$ in a medium containing $0.5 \mathrm{mg}$ DNA per ml. An abnormal mitotic figure is shown in which the chromatin is dispersed in the form of small granules.

FIgs. $P, Q$ and $R$. Three different regions in the extra-embryonic tissue of a 6 -day rabbit blastocyst incubated for $7 \mathrm{hr}$ in normal medium in the absence of $\mathrm{O}_{2}$ (gas mixture of $95 \% \mathrm{~N}_{2}+5 \% \mathrm{CO}_{2}$ ). There is a progressive decrease in vacuolization from the embryonic pole towards the abembryonic one. Fig. P, close to the embryonic disc. Fig. $Q$, at lower edge of endoderm; Fig. R, trophoblast at abembryonic pole. 